\title{
Verification of Scale Effect of Shallow Foundation in Determination of Bearing Capacity of Sandy Soil
}

\author{
Dr. Hussein M. Al.Khuzaie (PhD, C.E) \\ Ass. Prof., Foundation of Technical Education/ Samawa Technical Institute
}

\begin{abstract}
The strength parameters for sandy soil are not depending mainly on level of stresses but they are a linear function of width (B) and embedment depth $\left(\Delta_{u}\right)$ of footing in Terzaghi's solution of bearing capacity. On the other hand, it was found by as called the non-classical solution conducted by Parkins and Madson (1997) that this relation is nonlinear and the bearing capacity for sandy soil is mainly relating to width and depth of foundation, which is known as scale effect. In this work a field model test was carried out on compacted sandy soil bed for different types of footings with different sizes and geometry for clarification of the two aforementioned approaches. It was found that two approaches are consistent and indicating the scale effect well for bearing capacity of sandy soil. On the other hand, from the field model tests results, it is found that the two determinations give overestimated bearing capacity values, especially for rectangular footing with length to width ratio more than $5(\mathrm{~L} / \mathrm{B}>5)$ specially by Parkins and Madson's approach rather than the Terzaghi's equation.
\end{abstract}

Keywords: Bearing Capacity, Cohesion and Secant Internal Friction angle, Dilatancy, Scale Effect, Shear Strength

$$
\begin{aligned}
& \text { التحقق من تأثير المقياس على حساب تحمل التربة الرملية }
\end{aligned}
$$

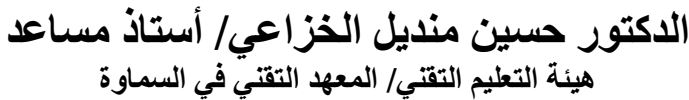

$$
\begin{aligned}
& \text { الخلاصة }
\end{aligned}
$$

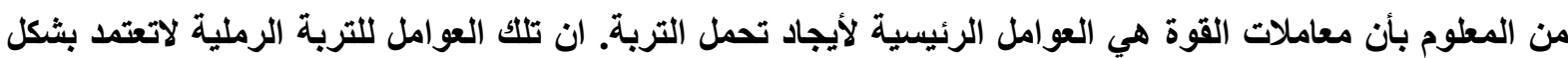

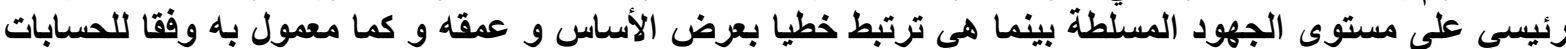

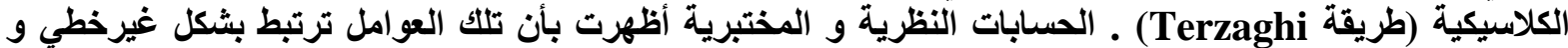

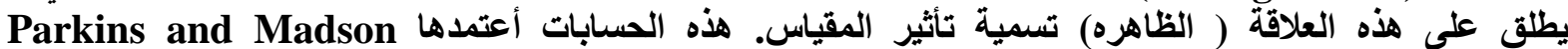

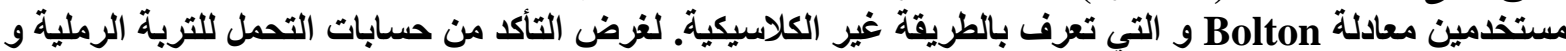

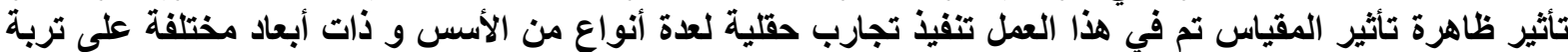

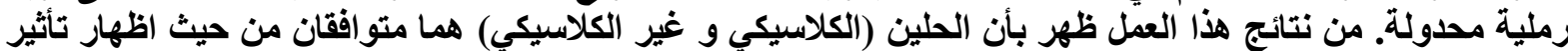

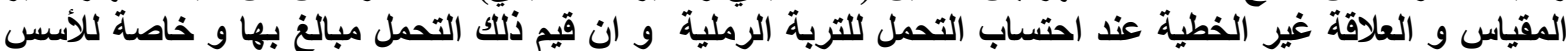

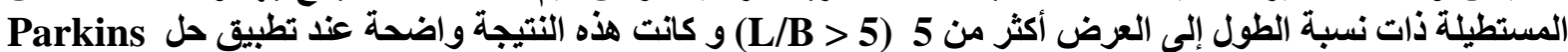
and Madson. 


\section{Introduction:}

The bearing capacity of sand is a function of dimensions and shape of foundation, embedment depth, physical and mechanical parameters of soil and load geometry. Experimental verification of methods of the bearing capacity determining used in engineering practice is usually made on small dimension foundation models set on the surface of soil. Full-scale tests are very expensive and rarely made. This is the reason why scale effect is very important while interpreting the results of tests.

The following basic factors inducing scale effect in the classical Terzaghi's solution and in the non-classical Parkins and Madson's proposition are; [1] and [2]:

\section{1- Strength parameters of sandy soil:}

Cohesion(c) and internal friction angle $(\emptyset)$ are primary strength parameters of soils. Two types of cohesion occur for sand: apparent cohesion induced by water meniscus between individual grains of sand and calculated cohesion which is an effect of linear approximation of the failure envelope. For small foundations even very small cohesion $(1.5 \mathrm{kPa})$, influences the bearing capacity [3]. Two definitions of sand strength parameters [4] obtained from direct shear tests are presented in Fig. 1. For the given normal stress $\left(\sigma_{M}\right)$ the straight line which passes through the origin of coordinates and point $\mathrm{M}$ (approximation $\mathrm{c}=0$ ) defines the secant angle of internal friction $\left(\emptyset_{\mathrm{s}}\right)$. The normal stress $\left(\sigma_{M}\right)$ should be chosen in a manner to be representative stress because it will be used to

$\sigma_{\mathrm{m}}=\alpha \mathrm{q}_{\mathrm{u}}$

, where: $\alpha$ is a certain coefficient and equals $1 / 10$ according to De Beer, [5] and $\mathrm{q}_{\mathrm{u}}$ the bearing capacity of foundation.

Internal friction angle $\emptyset$ ) is determined by a straight line in the approximation of the MohrCoulomb failure envelope. Strength parameters determined in this way do not depend on stresses. Currently, the design calculations of bearing capacity of shallow and deep foundations on granular soils do not consider any scale effects between the soil and the foundation structure; this can give a conservative design, which in turn results in excessive costs of foundations [6] and [7].

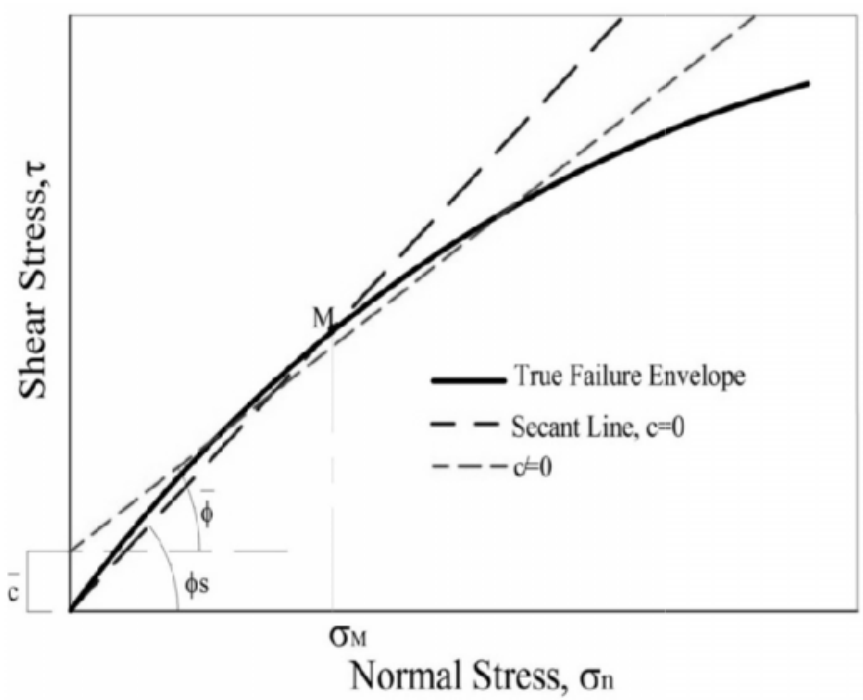

Figure 1: Illustration of approximation $\mathrm{c}=0$ and c $\nexists$ (after Kutter et al. 1988) 


\section{2-Depth of embedment}

Scale effect caused by a very small depth of embedment which is a result of foundation settlement $\left(\Delta_{\mathrm{u}}\right)$ at ultimate load (Fig. 2), [7].

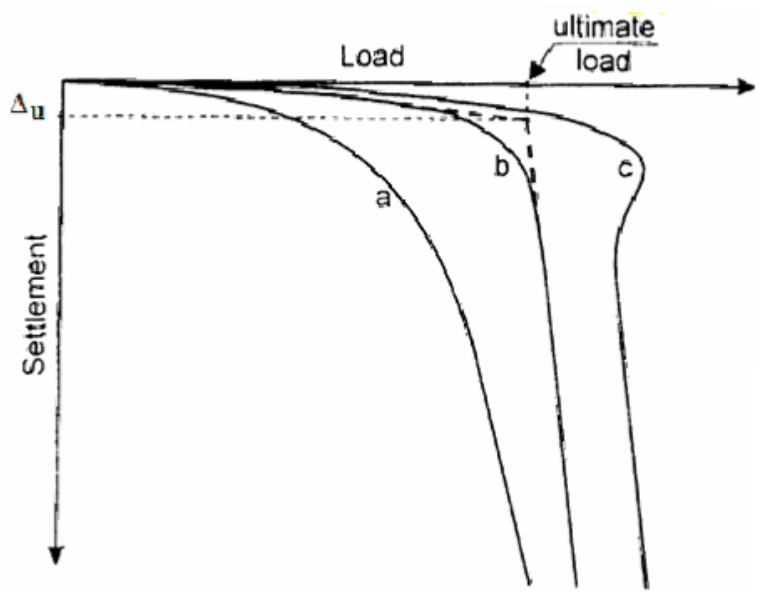

Figure 3: Typical load-settlement graphs for sandy soil

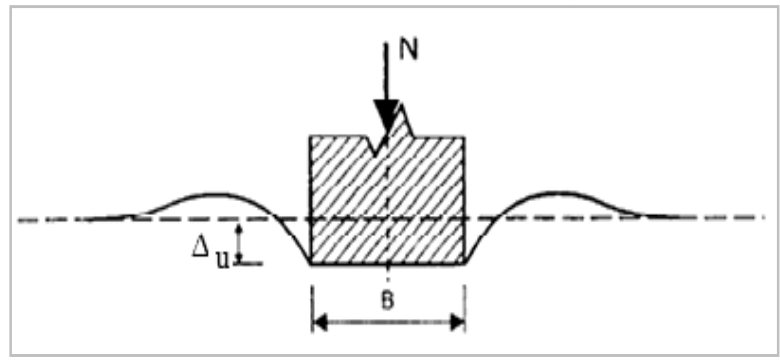

Figure 2: Typical deformation of base soil.

Typical dependencies of foundation settlement $(\Delta)$ (if the foundation on the surface) on vertical load $(\mathrm{N})$ for sand of different degree of compaction are presented in Fig. 3. The curve (a) illustrates dependencies for loose sand, (b) for medium sand and (c) for dense sand.

\section{3-Non-uniformity of plastic deformations}

Theoretical and experimental results show that the zones of plastic deformations occur at first near the border of foundation and then enlarge as load increases. As a result maximum and minimum shear resistances occur only in some points of plastic deformation zone whereas intermediate values are reached in other points. Observed bearing capacity of soil makes only some percentage of capacity corresponding with peak (maximum) shear resistances. Non-uniformity of distribution of plastic deformations is greater for bigger foundations than small ones. The difference between maximum and minimum (residual) states depends on the initial void ratio of sand and this is the reason why scale effect caused by non-uniformity of deformations depends not only on dimensions of footing but also on the initial void ratio, [5].

\section{Scope of the Current Study:}

Results of field tests of the bearing capacity of three types (rectangle, square and circle) small foundations on sand are described and analyzed in this work. In the field model tests described in this work the curve of type (b) in (Fig.3) were obtained for which the curve load-settlement was approximated by two straight lines. The point of intersection of these lines defines ultimate load and corresponding settlement $\Delta_{\mathrm{u}}$ as shown in figure 3 . The determinations of bearing capacity for these foundations were 
compared with those resulting by classical (Terzaghi) and no-classical (Parkins and Madson) calculations. It was found that the non-classical solution give higher values for bearing capacity of rectangular footing than those calculated by classical and found in the field model. It can be noticed for the other two types of footing that the results are consistent.

\section{The Classical Method:}

The solution based on the Terzaghi's proposition where the bearing capacity is a sum of three components expressing accordingly the influence of the footing width (B), the depth of embedment $\left(\Delta_{\mathrm{u}}\right)$ and cohesion (c) is considered as classical. The equation used for the estimation of the ultimate bearing capacity $\left(\mathrm{q}_{\mathrm{u}}\right)$ of vertically loaded foundation [1] is:

$\mathrm{q}_{\mathrm{u}}=0.5 \gamma \mathrm{BN}_{\gamma} \mathrm{S}_{\gamma}+\gamma \mathrm{DN}_{\mathrm{q}} \mathrm{S}_{\mathrm{q}}+\mathrm{cN}_{\mathrm{c}}$

where:

$$
\begin{array}{lll}
\mathrm{N}_{\mathrm{q}}=\mathrm{e}^{\pi \tan \gamma} \tan ^{2}\left(\frac{\pi}{4}+\frac{\varnothing}{2}\right) & . \mathrm{N}_{\gamma}=\left(\mathrm{N}_{\mathrm{q}}-1\right) \tan \varnothing & \mathrm{N}_{\mathrm{c}}=\frac{\left(\mathrm{N}_{\mathrm{q}} \mathrm{S}_{\mathrm{q}}-1\right)}{\tan \gamma} \\
\mathrm{S}_{\gamma}=\frac{1}{1+\mathrm{b}} & \mathrm{S}_{\mathrm{q}}=1+1.6 \tan \varnothing \frac{\mathrm{b}}{1+\mathrm{b}^{2}} & \mathrm{~b}=\frac{\mathrm{B}}{\mathrm{L}}
\end{array}
$$

In all the above relations, $\mathrm{N}_{\mathrm{q}}, \mathrm{N}_{\gamma}$ and $\mathrm{N}_{\mathrm{c}}$ are $\mathrm{N}$ factors for surcharge load $(\mathrm{q}=\gamma \times$ depth of base of foundation), unit weight of soil $(\gamma)$ and cohesion (c) respectively, while $S_{q}$ and $S_{\gamma}$ are the shape factors of surcharge load and unit weight of soil respectively. In addition $\emptyset$ is the internal friction angle, B and L are the width and length of the foundation respectively.

Consideration of cohesion $(\mathrm{C} \neq)$ ) considerably increases the bearing capacity of foundation on sand. In practice "cohesion" is disregarded in calculation and obtained capacities are considerably lower. It can be concluded that for granular soils the bearing capacity is mainly depending on the term of the unit weight. So this term is dependent on the absolute width of the foundation (B) (e.g., Cerato and Lutenegger, [8] ; Hettler and Gudehus 1988 [9]; Ueno et al. 1998, [10]; Ueno 2001 [11] and Zhu et al. 2001 [12].

\section{The Non-Classical Method (Parkins and Madson's Proposition):}

A granular soil may experience two types of shear when subject to shearing deformation depending on its density. First one is known as dilatancy, i.e. the soil tends to expand in volume when it is dense and in the second type of shearing is simple shear and the soil may be near its critical state (near the failure envelope) when it is loose (low density), [1].

Figure (4) shows this behavior schematically. From this figure it can be concluded that the peak angle of friction $\left(\phi_{\text {Peak }}\right)$ is the summation of critical friction angle $\left(\phi_{C V}\right)$ and dilatancy friction angle $(\psi)$. As stated by Bolton (1986) [13] this definition can be expressed by the following equation:

$$
\varnothing_{\text {Peak }}=\varnothing_{C V}+\psi
$$




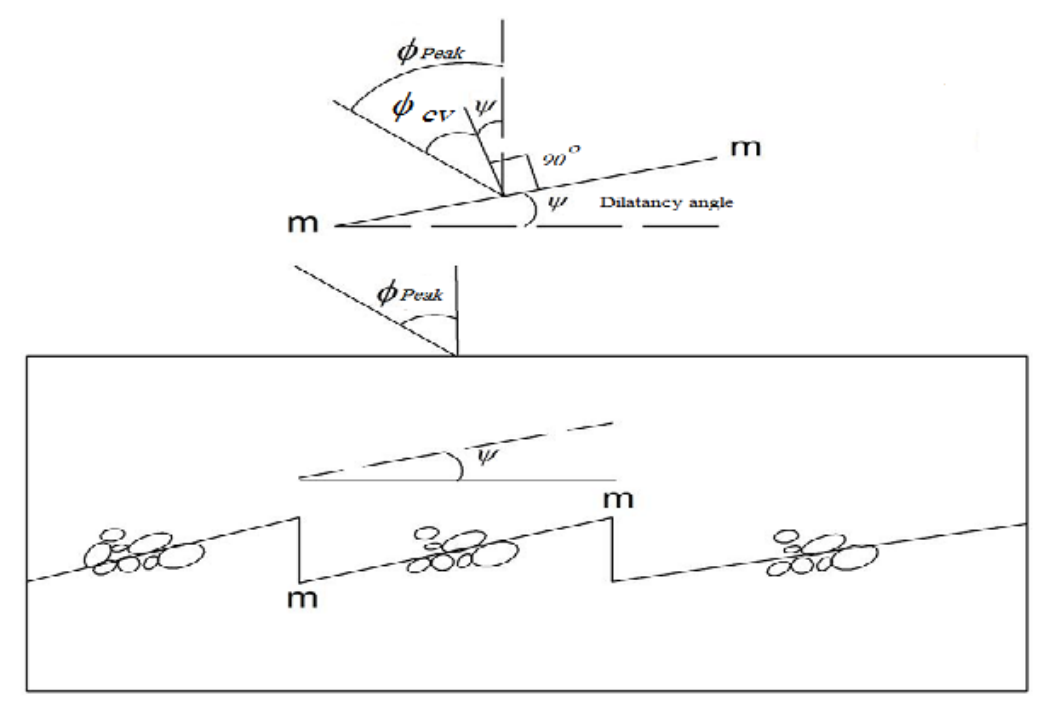

Figure 4: Schematic diagram for peak (max.) friction angle related to critical state friction angle and dilatancy angle (Reproduced from Bolton, 1986)

When the soil is of enough density ( dense soil), the tendency towards dilation i.e. the density is a function of dilatancy and when the arrangement of soil particles in pattern to permit them override each other during shearing causing increasing the volume [13]. A relative dilatancy index was derived as follows according to Bolton (1986), [13]:

$\varnothing_{\text {peak }}=\varnothing_{c v}+A^{\prime} I_{R}$

Relative dilatancy index $\left(\mathrm{I}_{\mathrm{R}}\right)$ :

$I_{R}=I_{D}\left(10-\ln p^{\prime}\right)-1$

where: $\quad \mathrm{p}^{\prime}=\frac{1}{3}\left(\sigma_{1}^{\prime}+\sigma_{2}^{\prime}+\sigma_{3}^{\prime}\right)$

Index $\mathrm{A}^{\prime}$ should equal 5 for plane strain and 3 for axial symmetry conditions. Parkins and Madson (1997), [2], accept that:

$$
A^{\prime}=\frac{1}{3}\left(\frac{L}{B}+8\right)
$$

what means that $\mathrm{A}^{\prime}=5$ for $\mathrm{L} / \mathrm{B} \geq 7$ and $\mathrm{A}^{\prime}=3$ for $\mathrm{L}=\mathrm{B}$

Parkins and Madson (1997) [2 ] based on the Bolton's empiric dilatation equation [13] found that:

$$
\mathrm{p}^{\prime}=\frac{1}{6} \overline{\mathrm{q}}_{\text {u peak }}\left(0.52-0.04 \frac{\mathrm{L}}{\mathrm{B}}\right)
$$

The baring capacity is described by the equation:

$\mathrm{q}_{\mathrm{u}}=\mathrm{I}_{\mathrm{PF}}\left(\mathrm{q}_{\mathrm{u} \text { peak }}-\overline{\mathrm{q}}_{\mathrm{u} \mathrm{cv}}\right)+\overline{\mathrm{q}}_{\mathrm{u} \mathrm{cv}}$ 
The values ( $\left.\overline{\mathrm{q}}_{\text {upeak }}\right)$ are for maximum values $\left(\varnothing_{\mathrm{s}}=\varnothing_{\text {peak }}\right)$ and $\overline{\mathrm{q}}_{\mathrm{ucv}}$ are for critical values $\left(\varnothing_{\mathrm{s}}=\varnothing_{\mathrm{cv}}\right)$ described by the equation (8):

$\mathrm{q}_{\mathrm{u}}^{-}=\gamma \mathrm{DN}_{\mathrm{q}}^{-}+\frac{1}{2} \gamma \mathrm{BN}_{\gamma}^{-}$

$\left(\varnothing_{\mathrm{s}}\right)$ is the secant internal friction angle, and $\mathrm{N}_{\mathrm{q}}^{-}$and $\mathrm{N}_{\gamma}^{-}$can be calculated by the following relations:

$\overline{\mathrm{N}}_{\mathrm{q}}=\mathrm{e}^{\pi \tan \otimes^{\mathrm{g}}} \tan ^{2} \beta$

where:

$\ell^{\mathrm{g}}$ : The secant angle of internal friction, either it is $\varnothing_{\text {peak }}$ or equals to $\varnothing_{\mathrm{cv}}$ according to its using in the equation as per the status of application.

$$
\begin{aligned}
\overline{\mathrm{N}}_{\gamma}=\frac{1}{2} \tan \beta( & \left.\tan \beta \mathrm{e}^{\frac{3 \pi}{2} \tan \emptyset^{\mathrm{g}}}-1\right) \\
& +\frac{3 \sin \emptyset^{\mathrm{g}} \cos \emptyset^{\mathrm{g}}}{2\left(1+8 \sin ^{2} \emptyset^{\mathrm{g}}\right)\left(1-\sin \emptyset^{\mathrm{g}}\right)}\left[\mathrm{e}^{\frac{3 \pi}{2} \tan \emptyset^{\mathrm{g}}}\left(\tan \beta-\frac{1}{3} \cot \emptyset^{\mathrm{g}}\right)\right. \\
& \left.+\tan \beta \frac{\cot \emptyset^{\mathrm{g}}}{3}\right] \quad \text { and } \quad \beta=\frac{\pi}{4}+\frac{\emptyset^{\mathrm{g}}}{2}
\end{aligned}
$$

The value of index of progressive failure $\left(I_{P F}\right)$ was determined after analysis of results of 70 experiments carried out by Parkins and Madson (1997), [2]. The dependency of index $\left(I_{P F}\right)$ on relative density $\left(I_{R}\right)$ is shown in Fig. 5. It is recommended to take for calculation values presented in broken line as shown in this figure.

The values of $\mathrm{p}^{\prime}$ and $e^{\mathrm{g}}$ are calculated for each loading process, which was applied in stepwise of vertical loading. The bearing capacity is calculated from the equation (8) for these two parameters.

\section{The Field Model Tests:}

In order to evaluate the impact the geometry and size of footing and its depth of embedment on the bearing capacity factors, field model load test was executed on the surface of a soil which is mainly sand soil, the bed for construction of electricity power

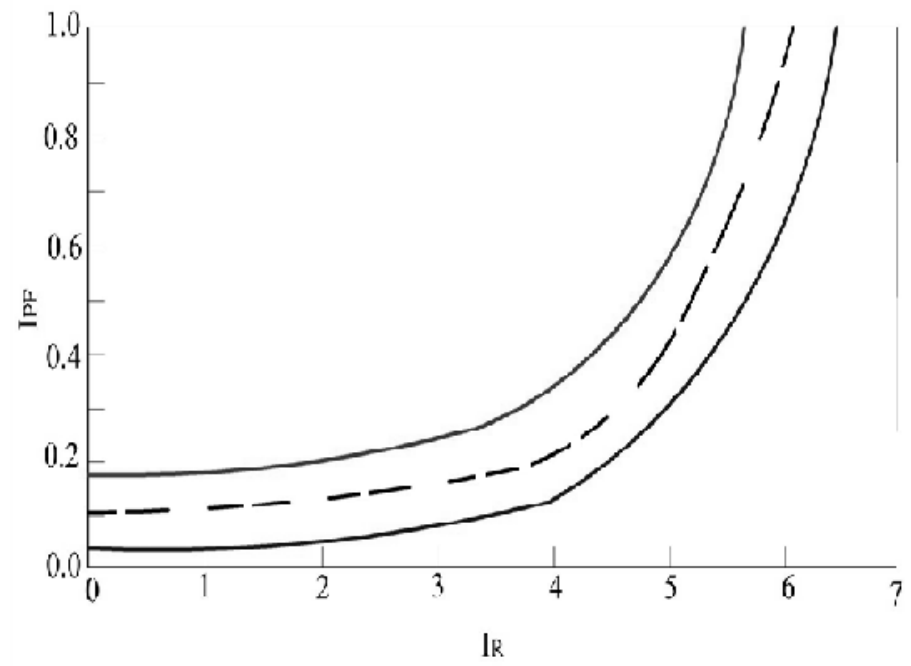

Figure 5: Dependence of index of progressive failure on relative dilatancy index (after Parkins and Madson, 1997). generation plant. This project was implemented by Al.Rafid Group in partial of Japanese Grant with the main contractor Marubeni Corporation Company in al-Samawah city). It was done in the 
period of construction as the author worked as consultant for the project. The field tests were conducted by equipments and accessories are similar to that used in load test procedure furnished by Anderea Laboratory in Baghdad with some modifications to be suitable the site and loading conditions.

\section{1-Physical Properties of Investigated Soil:}

The physical properties of the soil in the bed of the site of the project are summarized as: it is granular soil of well graded course- medium sand with coefficient of uniformity 2.6 and fines $(<0.074 \mathrm{~mm})=2 \%$, water $\operatorname{content}\left(\mathrm{W}_{\mathrm{n}}\right)=$ $3.5 \%$ and it is classified as non-plastic soil, bulk unit weight $(\gamma=17 \mathrm{kN} / \mathrm{m} 3)$, relative density $\left(I_{D}=0.82\right)$. This stratum is of $4 \mathrm{~m}$ thick.

\section{2-Shear Strength Parameters of the Soil:}

A direct shear tests were carried out on samples have been taken from the soil of the project site to investigate the shear strength parameters at the same relative density $\left(I_{D}=0.82\right.$ with variance $\left.\sim 0.05\right)$ used in the field compaction. This investigation was performed in accordance of procedure described by ASTM D 3080 [14] utilizing direct shear machine manufactured by ELE (G.B) in the laboratories belongs to college of engineering in al.Kufa University, Iraq under the supervision of the author. The results of direct shear tests of this soil and non-linear approximation of the failure envelope are shown in Fig. 6.

The dependency of maximum shear stress $(\tau)$ on normal stresses was found to be expressed by equation (10).

$\tau=\sigma_{\mathrm{n}} \tan \varnothing_{\mathrm{S}}$

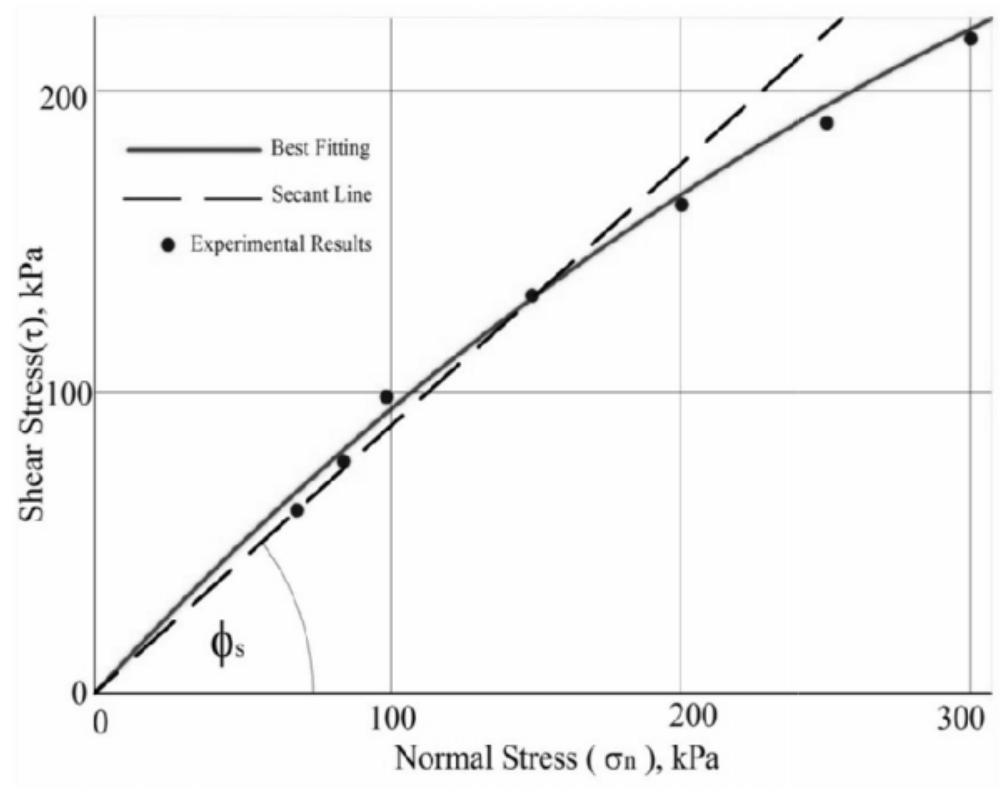

Figure 6: The results of direct shear tests in the current investigation

Then the secant angle of internal friction $\left(\varnothing_{S}\right)$ is determined by equation (11):

$\varnothing_{\mathrm{S}}=f-k \ln \sigma_{\mathrm{n}}$

where $f$ and $k$ are constants and expressed in degrees. 
Equation (11) was created by drawing the relation between the secant angle of internal friction $\varnothing_{\mathrm{S}}$ (in degrees) and the normal stress $\sigma_{\mathrm{n}}(\mathrm{kPa})$ in $\log$ scale as shown in Fig. 7. From the best non-linear approximation is obtained for $f=64.06^{\circ}$ and $k=$ $4.72^{\circ}$.

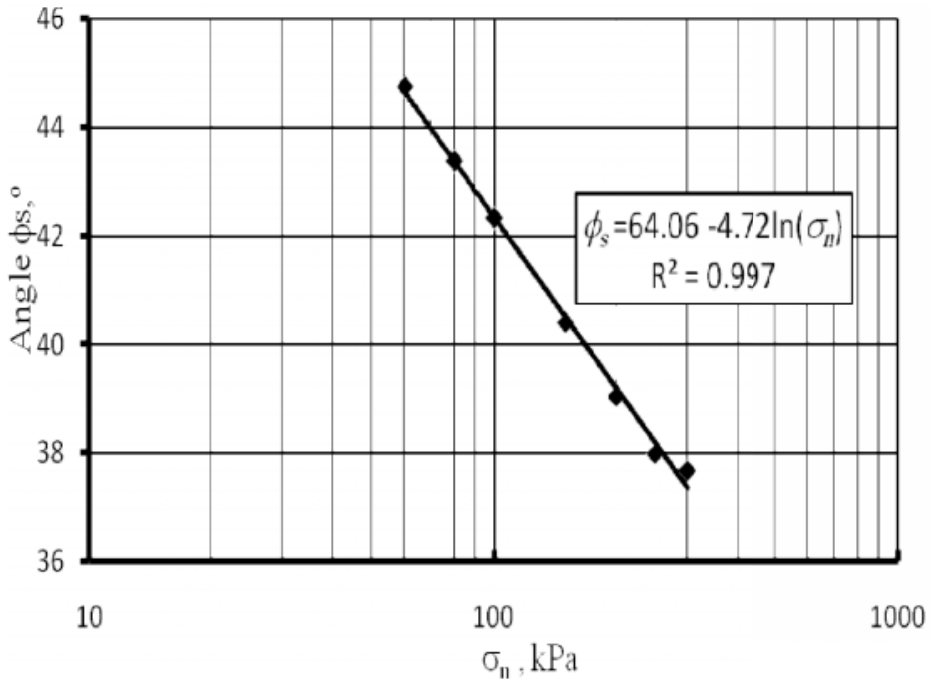

Figure 7: The dependency of the secant angle $\left(\phi_{s}\right)$ on normal stress $\left(\sigma_{\mathrm{n}}\right)$

\section{3- Geometry of Footings which were tested in the Current Work:}

Small foundations ( 3 rectangles, 2 squares and 2 circles) of dimensions and areas as shown in table (1) were tested in the field by the same procedure used in load test method. These footings were located on the horizontal surface of compacted sandy soil layer (the current soil in the project) and slowly vertical forces were applied at centerline axis of each one.

Table 1: The Geometry of foundations.

\begin{tabular}{|c|c|c|c|}
\hline \multirow[t]{2}{*}{ No of Foundation } & & Foundation & \multirow{2}{*}{$\begin{array}{c}\mathrm{A} \\
\mathrm{cm}^{2}\end{array}$} \\
\hline & Type & Dimension, $\mathrm{cm}$ & \\
\hline 1 & \multirow{3}{*}{ Rectangle } & $10.0 \times 46.6$ & 466 \\
\hline 2 & & $14.0 \times 71.4$ & 1000 \\
\hline 3 & & $22.0 \times 113.0$ & 2486 \\
\hline \multirow[t]{2}{*}{4} & \multirow[t]{3}{*}{ Square } & Side length & \multirow[t]{2}{*}{912} \\
\hline & & 30.2 & \\
\hline 5 & & 50.0 & 2500 \\
\hline \multirow[t]{2}{*}{6} & \multirow[t]{3}{*}{ Circle } & Diameter & \multirow[t]{2}{*}{995} \\
\hline & & 35.6 & \\
\hline 7 & & 56.4 & 2500 \\
\hline
\end{tabular}

\section{Results:}

The bearing capacities $\mathrm{q}_{\mathrm{u}}$ and corresponding settlements $\Delta_{\mathrm{u}}$ are given in Table 2 as calculated from the field readings and plotted curves between vertical stress and settlement in the same way for drawing shown in figure 3 , curve $b$. 
Table 2: Field Test Results.

\begin{tabular}{|c|c|c|}
\hline No of Foundation & $\begin{array}{c}\mathrm{q}_{\mathrm{u}} \\
\mathrm{kPa}\end{array}$ & $\Delta_{\mathrm{u}}, \mathrm{cm}$ \\
\hline 1 (Rect.) & 272.5 & 2.17 \\
\hline 2 (Rect.) & 250.0 & 2.67 \\
\hline 3 (Rect.) & 249.4 & 3.12 \\
\hline 4 (Square) & 405.0 & 2.70 \\
\hline 5 (Square) & 449 & 3.88 \\
\hline 6 (Circle) & 360.0 & 3.25 \\
\hline 7 (Circle) & 460.0 & 3.75 \\
\hline
\end{tabular}

The normalized by the term $\gamma \mathrm{B}$ bearing capacities of the foundation No 3 calculated according to the classical and non-classical method for strength parameters of sand ( $\varnothing_{\mathrm{S}}$ ) and embedment depths D are presented in Table 3. The values of secant angle of internal friction $\left(\varnothing_{\mathrm{S}}\right)$ in the classical method (Terzaghi's approach) for $\sigma_{\mathrm{m}}=0.25 \mathrm{q}_{\mathrm{u}},(\alpha=0.25)$ and $\sigma_{\mathrm{m}}=0.5 \mathrm{q}_{\mathrm{u}},(\alpha=0.5)$ are $44.6^{\circ}$ and $41.3^{\circ}$ respectively.

Table 3: The bearing capacity normalized by the term $\gamma \mathrm{B}$ for third Foundation.

\begin{tabular}{|c|c|c|c|c|c|c|c|c|}
\hline \multirow{2}{*}{$\begin{array}{l}\text { Foundation } \\
\text { No } 3 \\
\text { B x L }\end{array}$} & \multirow{2}{*}{$\begin{array}{c}\Delta_{\mathrm{u}} \\
\mathrm{m}\end{array}$} & \multicolumn{3}{|c|}{ Terzaghi's Approach } & \multicolumn{3}{|c|}{ Perkins and Madison's Method } & \multirow{2}{*}{$\begin{array}{c}\text { Field } \\
\text { Test } \\
\text { Result } \\
\mathrm{q}_{\mathrm{u}} \cdot / \gamma \mathrm{B}\end{array}$} \\
\hline & & $\alpha$ & $\ell_{S}$ & $\mathrm{q}_{\mathrm{u}} \cdot / \gamma \mathrm{B}$ & $\emptyset_{C V}$ & $\mathrm{I}_{\mathrm{D}}$ & $\mathrm{q}_{\mathrm{u}} \cdot / \gamma \mathrm{B}$ & \\
\hline $\mathrm{m} \times \mathrm{m}$ & & - & o & - & o & - & - & 66.7 \\
\hline \multirow[t]{4}{*}{$0.22 \times 1.13$} & 0.031 & \multirow[t]{2}{*}{0.25} & \multirow[t]{2}{*}{44.6} & 67.6 & \multirow[t]{2}{*}{33.5} & \multirow[t]{4}{*}{0.82} & 131.1 & \\
\hline & 0 & & & 49.7 & & & 125.7 & \\
\hline & 0.031 & \multirow[t]{2}{*}{0.5} & \multirow[t]{2}{*}{41.3} & 37.6 & \multirow[b]{2}{*}{32} & & & \\
\hline & 0 & & & 28 & & & 107 & \\
\hline
\end{tabular}

The value of internal friction angle in the critical state $\left(\emptyset_{C V}\right)$ is accepted to equal residual angle of friction $\emptyset_{r}$. The bearing capacity was also calculated for $\varnothing_{C V}=32^{\circ}$ because the values for $\varnothing_{C V}$ obtained in triaxial tests could be a little lower than that determined in plane strain [15].

The bearing capacities calculated by the non-classical method are several times higher (overestimated) values than those determined by classical empirical approach and also than the values obtained by field model test. The calculated values in classical method are the closest to the field values for internal friction secant angle $\varnothing_{\mathrm{S}}$ $=44.6^{\circ}$ obtained for $\alpha=0.25$ and embedment depth $\mathrm{D}=\Delta_{\mathrm{u}}=0.031 \mathrm{~m}$ as shown in table 3 .

For further analysis it can be used the ratio between the embedment in critical state for rectangular foundations of $(\mathrm{L} / \mathrm{B}=5)$ to width was 0.15 , for square foundations 0.1 and for circle foundations 0.177 . The internal friction secant angle was calculated for $\alpha=0.25$. Internal friction angle in critical state $\varnothing_{C V}$ $=\emptyset_{r}=33.5^{\circ}$, unit weight $\gamma=17 \mathrm{kN} / \mathrm{m}^{3}$ and relative density $\left(\mathrm{I}_{\mathrm{D}=} 0.82\right)$. The Dependency 
of the bearing capacity normalized by the term $\gamma B$ on the width of foundation $B$ (scale effect) in the classical and non-classical method comparing with the field test results is shown in Fig. 7.

Scale effect in the case of square (circle) foundations is nearly the same for the classical and non-classical method, while in the case of rectangular foundations $(\mathrm{L} / \mathrm{B}=5)$ the scale effect is more obvious for the non-classical (Perkins and Madson's) method than the classical method. Field model test data shows that the classical method is more correct for rectangular foundations. The above results are different than the results that obtained by Cerato and Lutenegger, 2007, [8] which were carried out on laboratory models for granular soil. They concluded that their small footings were shown to have low mean stresses but high $\mathrm{N} \gamma$ values and they related this phenomena to the curvature of the Mohr-Coulomb failure envelope. Meanwhile the work of later authors [8] confirmed the current investigation which conducted on sand soil, when the relation between normal and shear stresses near the critical state is not linear but it is curvilinear.
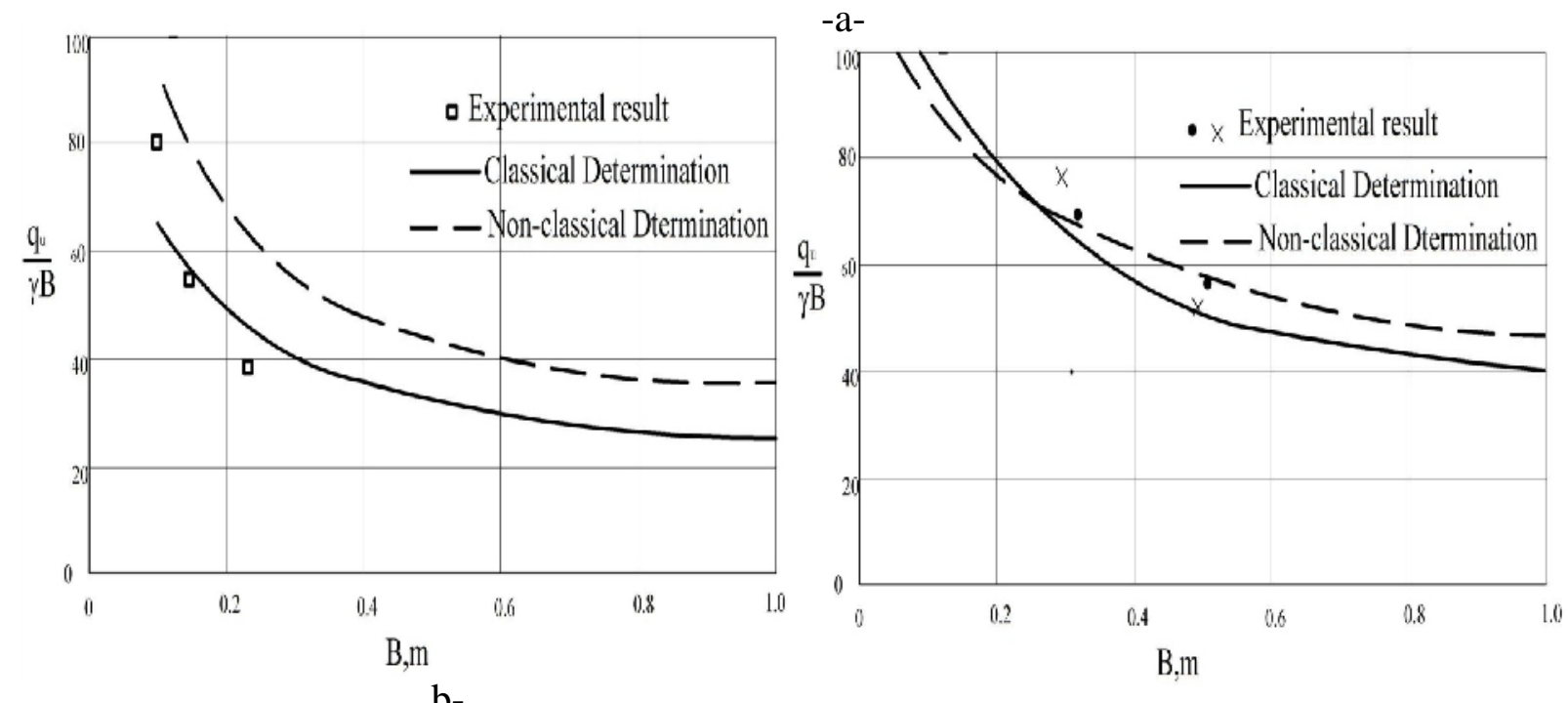

Figure 8: Normalized bearing capacity: a) rectangular foundations: b) square and circle foundations.

\section{Conclusions:}

1) The field model test that was performed in this work for sand soil indicates that:

1- The bearing capacity factor $(\mathrm{N} \gamma)$ is dependent on the width of footing.

2- Small embedment (even though few centimeters) affects considerably the bearing capacity for small foundations.

3- Consideration of dilatancy effect in non-classical Parkins and Madson's approach will cause in overestimation of the bearing capacity for rectangular footings ( $\mathrm{L} / \mathrm{B}>5)$ rather than determination by classical Terzaghi's equation for the same type of footing.

4- The bearing capacity in general has consistent values for circulare and square foundations as determined by classical and non-classical solutions and it is of low discrepancy with that found in the field model tests.

2) The stress dependency may also be related to the curvature of Mohr-Coulomb failure envelope where high friction angles at low stresses and low friction angles at high mean stresses have been observed. This curvature of Mohr-Coulomb envelope has been well 
documented and helps to explain why small footings have large $\mathrm{N} \gamma$ values, and hence, large friction angles corresponding to the dense state of soil in relation $(\psi)$ to critical state line.

3) When using model-scale footing tests in lieu of more expensive full scale footing tests, it is recommended to investigate the effect of both the grain size and the density of the sand in determination of bearing capacity of this type of soils.

\section{REFERENCES}

1. Terzaghi, K., Peck, R. B. and Mesri, G. Soil Mechanics in Engineering Practice, Wiley, New York, 1996.

2. Parkins, S.W. and Madson, C.R. "A dilatancy approach for the bearing capacity of sands", Proceedings of the Fourteenth International Conference on Soil Mechanics and Foundations Engineering, Hamburg 1997, pp. 1189-119.

3. Meyerhof, G.G. "Influence of roughness of base and groundwater conditions on the bearing capacity of foundations", Geotechnique, Vol. 5, No. 3, 1955, pp. 227-242.

4. Kutter, B.L., Abghari, A. and Chaney, I.A. "Strength parameters for bearing capacity of sand", Journal of Geotechnical Engineering, ASCE, Vol. 2, No. 4, 1988, pp. 301332.

5. De Beer, E. E. " The scale effect on the phenomenon of progressive rupture in cohesionless soils" Proceedings of $6^{\text {th }}$ international conference on soil mechanics and foundation engineering", Montreal, Canada, vol. 2, 1965, pp. 13-17.

6. Meyerhof, G.G. "The ultimate bearing capacity of foundations" Geotechnique, Vol. 2, No. 4, 1951, pp. 301-332.

7. Perau, E.W. "Bearing capacity of shallow foundations", Soil and Foundations, Vol. 37, No. 4, 1997, pp. 77-83.

8. Cerato, B. and Lutenegger J. "Scale effects of shallow foundation bearing capacity on granular material" J. Geotechnical and Geoenvironmental Engineering, ASCE, vol. 33, no. 10, 2007, pp. 1192-1202.

9. Hettler, A. and Gudehus, G. "Influence of the foundation width on the bearing capacity factor" J. Soils and Foundation, vol. 28, no. 4 , 1988, pp. 81-92.

10. Ueno, K. , Miura, K. and Maeda, Y. "Prediction of ultimate bearing capacity of surface footing with regard to size effects" J. Soils and Foundation, vol. 38, no. 3, 1998.

11.Ueno, K. "Methods for preparation of sand samples" Centrifuge 98, ISSMFE, Tokyo, Japan, vol. 2, 2001, pp. 1047-1055.

12.Zhu, F. Clark, J. I. and Philips, R. "Scale effect of strip and circular footings resting on dense sand" J. Geotechnical and Geoenvironmental Engineering, vol. 127, No. 7, 2001, pp. 613-621.

13. Bolton, M.D. "The strength and dilatancy of sands", Geotechnique 36, No. 1, 1986, pp. 65-78.

14. ASTM, "Direct Shear Test, D 3080", Califomia, USA, 2002

15. Bowles J. E. Physical and geotechnical properties of Soils, $4^{\text {th }}$ edition, McGraw Hill, New York, 1996. 